\title{
A Trigonometric Analytical Solution of Simply Supported Horizontally Curved Composite I-Beam considering Tangential Slips
}

\author{
Qin Xu-xi, Liu Han-bing, Wu Chun-li, and Gu Zheng-wei \\ College of Traffic, Jilin University, Changchun 130025, China \\ Correspondence should be addressed to Wu Chun-li; clwu@jlu.edu.cn
}

Received 27 March 2016; Revised 31 July 2016; Accepted 14 August 2016

Academic Editor: Leonid Shaikhet

Copyright (C) 2016 Qin Xu-xi et al. This is an open access article distributed under the Creative Commons Attribution License, which permits unrestricted use, distribution, and reproduction in any medium, provided the original work is properly cited.

\begin{abstract}
This paper presents an analytical solution of the simply supported horizontally composite curved I-beam by trigonometric series considering the effect of partial interaction in the tangential direction. Governing equations and boundary conditions are obtained by using the Vlasov curved beam theory and the principle of minimum potential energy. The deflection functions and the Lagrange multiplier functions are expressed as trigonometric series to satisfy the governing equations and the simply supported constraints at both ends. The numerical results of deflections and forces which are obtained by this method are compared with both FEM results and experimental results, and the inaccuracy between the analytical solutions in this paper and the FEM results is small and reasonable.
\end{abstract}

\section{Introduction}

A composite beam can be defined as "partially composite beam" when the number of shear connectors is less than the required number for fully composite design; therefore, the interface shear force is limited by the strength of shear connectors. In contrast to fully composite beam, slip between layers can be significant and results in a decrease in the elastic stiffness of partially composite beam. Composite beam exhibiting partial shear interaction will stand larger deflection than the beam exhibiting full shear interaction. By assuming complete shear interaction, the calculation of deflection for partial shear interaction beam is maybe underestimated. Because serviceability issues often govern the structural design of composite section, the accurate calculation of deflection is critical. The partial interaction is applied not only in steel-concrete composite beam, but also in other types of composite beams, such as layered wooden beams, wood-concrete floor systems, and other multilayered laminated composite structures $[1,2]$.

Earlier studies on behavior of the partially composite beam are mostly focused on the straight composite beam. The first paper dealing with the analysis of composite beam with partial interaction has been completed by Newmark et al. [3]. After that, Goodman and Popkov $[4,5]$ have conducted the analytical and numerical research on the relative slip between layers and found that the relative slip between layers has a significant effect on the overall characteristics of the composite beam with the reduction of shear connectors' stiffness. Girhammar et al. $[6,7]$ have applied a partial shear interaction theory for composite beam subjected to static loads and dynamic loads. Wang [8] has developed a method to calculate deflection of partially composite beam based on the stiffness of the shear connectors. Dall'Asta [9] has developed a three-dimensional theory for composite beam with partial shear interaction dealing with combination of bending in the symmetry plane, torsion, and transverse bending in the plane parallel to the shear connector interface. Nie and Cai [10] have studied the effects of shear slip on the deflection of steel-concrete composite beam. Ranzi and Bradford [11] have presented analytical solutions for time dependent behavior of partially composite beam. Liu et al. [12] have found out the solution of shearing slip for steel-concrete composite beam under the concentrated load. Campi and Monetto [13] have presented a new formulation to analyze two-layer linearly elastic Timoshenko beam with 
interlayer slip. In the aspect of numerical simulations studies, different kinds of numerical and finite element formulations for the analysis of composite beam with interlayer slip have been suggested [1, 14-19].

Many significant researches have been accomplished in regard to the behavior of straight partially composite beam. In the same time, various scholars have done researches on the curved beam theory. One of the earliest works dealing with the stability behaviors of curved beam has been put forward by Vlasov [20]. After that, scholars covered different extensions and enhancements to the Vlasov model [2126]. These researches are helpful to the development of the composite beam theory. However, very little literature has focused on the curved partially composite beam such as horizontally composite curved steel I-beam bridge. Thevendran et al. [27] and Shanmugam et al. [28] have conducted experiments on the steel-concrete composite curved beam to investigate the ultimate load behavior. In their study, the finite element software ABAQUS was used to analyze the behavior of test specimens. Full composite action between steel beam and the concrete slab was assumed. The results of deformations, stress distributions, and ultimate strengths obtained by finite element analysis were found to be in good agreement with the experimental results. After that, Topkaya et al. [29] have conducted experimental and numerical studies to establish the behavior of composite curved bridge during construction. In their study, two FEM models were established by different kinds of software to predict the behavior of the curved steel trapezoidal box-girder, and the authors have drawn a conclusion that the reasonable finite element model is able to accurately capture girder behavior during construction. Giussani and Mola [30] have developed an analytical equation for elastic composite beam curved inplane with the long term behavior. But the partial interaction between the steel girder and concrete slab was not considered in the study. Erkmen and Bradford [31] have solved the equation of the composite curved beam considering the two-layer partial interaction by providing a highly efficient $3 \mathrm{D}$ beam finite element. The results demonstrate that the developed formulation is accurate and effective in capturing the behavior of composite beams curved in-plane.

Even though some previous researches of these evaluation methodologies have been accomplished, there is still lack of the fundamental understanding of the system-level behavior on the overall performance of composite curved beam with partial shear interaction. Besides, although exact solutions can be obtained by the 3D finite element model, it is very complex and time consuming. Therefore, the FEM analysis procedures are not suitable for the initial design. This study aims to provide an analytical theory of the horizontally composite curved beam considering the partial interaction in tangential direction. The beam is assumed to be statically determinate with a constant radius of curvature along the longitudinal axis. Governing equations and boundary conditions are obtained by using both the Vlasov curved beam theory and the energy variation principle. The undetermined vertical deflection, torsional deflection, and Lagrange multipliers will be approximated by Fourier series to solve the governing equations of the partial interaction composite beam theory

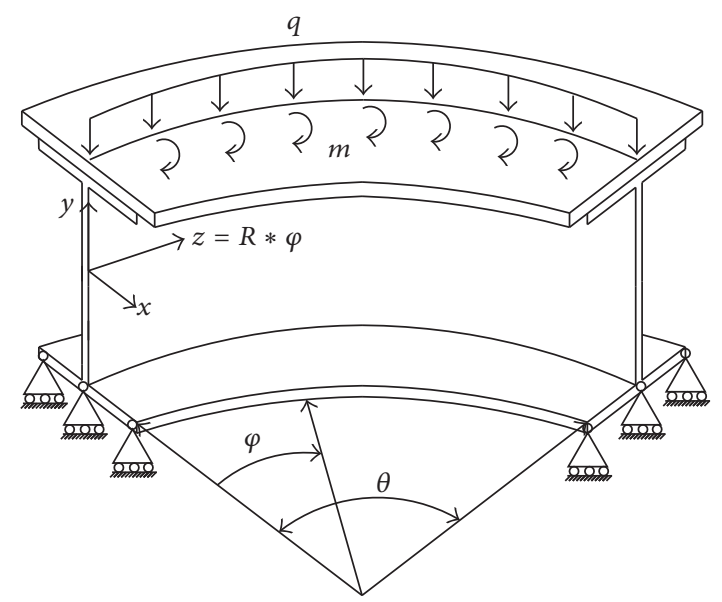

FIGURE 1: Model of a horizontally composite curved I-beam.

in the procedures. The numerical results of deflections and forces obtained by using proposed theory are presented and compared with FEM results and experimental results. Comparison results show that the calculation can be easily and accurately handled which is a great advantage of this method.

\section{Basic Assumptions and Conditions}

This study is on a horizontally composite curved I-beam where the model is shown as in Figure 1, and the noteworthy features of this research are shown as follows:

(1) The slab and I-girder are linear-elastic different materials, and the cross-sections made of both materials are rigid in their plane. The effects of shear deformation, warping deformation, and distortion deformation are neglected in this research. Structural analysis of the beam is based on the Vlasov curved beam theory (for each part of the beam).

(2) The interlayer connectors between the slab and Igirder are flexible, and they are continuous in tangential direction and rigid in radial direction. The load-slip behavior (per unit length) of connectors in tangential direction is described in a linear-elastic range with a constant slip modulus $K\left[\mathrm{~N} / \mathrm{m}^{2}\right]$.

(3) The uplift between the slab and I-girder is neglected. The radius of curvature is constant along the beam.

The deflections in tangential direction, vertical direction, and radial direction $(z$-direction, $y$-direction, and $x$ direction) are indicated as $u, w$, and $v$, respectively. The I-girder has the same torsional deflection $\phi$ and vertical deflection $w$ as the slab has. In this paper, subscript " 1 " refers to the cross-section of the slab and subscript " 2 " refers to the cross-section of I-girder, such that the deflections of the slab and I-girder can be represented as $\left(w, \phi, u_{1}, v_{1}\right)$ 
and $\left(w, \phi, u_{2}, v_{2}\right)$, respectively. The geometric relationships between strains and deflections may be written as

$$
\begin{aligned}
& \varepsilon_{z i}=u_{i}^{\prime}-\frac{v_{i}}{R}, \\
& k_{y i}=v_{i}^{\prime \prime}+\frac{u_{i}^{\prime}}{R}, \\
& k_{x i}=w^{\prime \prime}-\frac{\phi}{R}, \\
& k_{z i}=\phi^{\prime}+\frac{w^{\prime}}{R}
\end{aligned}
$$

$$
(i=1,2) \text {, }
$$

where $\varepsilon_{z i}$ is the axial strain, $k_{y i}$ is the curvature in $y$-direction, $k_{x i}$ is the curvature in $x$-direction, and $k_{z i}$ is the curvature in $z$-direction. Where ()$^{\prime}=d() / d z,()^{\prime \prime}=d^{2}() / d z^{2}$.

The constitutive equations are as follows:

$$
\begin{aligned}
N_{i} & =E_{i} A_{i} \varepsilon_{z i}, \\
M_{y i} & =E_{i} I_{y i} k_{y i}, \\
M_{x i} & =E_{i} I_{x i} k_{x i}, \\
T_{i} & =G_{i} I_{T i} k_{z i}
\end{aligned}
$$

$$
(i=1,2) \text {, }
$$

where $N_{i}, M_{y i}, M_{x i}$, and $T_{i}$ are internal axial force in $z$ direction, internal bending moment in $y$-direction, internal bending moment in $x$-direction, and internal torsion moment in $z$-direction, respectively.

The microunit's force diagram of the horizontally composite curved I-beam is shown in Figure 2, which is under the external distribution force $q_{0}$ and torsion moment $m_{0}$. The balance equations of the slab are

$$
\begin{aligned}
\frac{d Q_{x 1}}{d z}+\frac{N_{1}}{R}+q_{x 1} & =0, \\
\frac{d N_{1}}{d z}-\frac{Q_{x 1}}{R}+q_{z 1} & =0, \\
\frac{d M_{y 1}}{d z}+Q_{x 1} & =0 \\
\frac{d Q_{y 1}}{d z}-q_{0}+q_{y 1} & =0 \\
\frac{d M_{x 1}}{d z}+\frac{T_{1}}{R}-Q_{y 1}+m_{x 1} & =0 \\
\frac{d T_{1}}{d z}-\frac{M_{x 1}}{R}+m_{z 1}+m_{0} & =0
\end{aligned}
$$

The balance equations of the I-girder are

$$
\begin{aligned}
\frac{d Q_{x 2}}{d z}+\frac{N_{2}}{R}+q_{x 2} & =0, \\
\frac{d N_{2}}{d z}-\frac{Q_{x 2}}{R}+q_{z 2} & =0, \\
\frac{d M_{y 2}}{d z}+Q_{x 2} & =0, \\
\frac{d Q_{y 2}}{d z}+q_{y 2} & =0, \\
\frac{d M_{x 2}}{d z+\frac{T_{2}}{R}-Q_{y 2}+m_{x 2}}= & 0, \\
\frac{d T_{2}}{d z}-\frac{M_{x 2}}{R}+m_{z 2} & =0,
\end{aligned}
$$

where $m_{x i}$ is the distributed bending moment caused by shear force $q_{z i}, m_{z i}$ is distributed torque caused by shear force $q_{x i}$, $Q_{x i}$ is the shear force in $x$-direction, and $Q_{y i}$ is the shear force in $y$-direction. For the shear forces $q_{z i}, q_{x i}$, and $q_{y i}$, there are

$$
\begin{aligned}
& q_{z 1}+q_{z 2}=0, \\
& q_{x 1}+q_{x 2}=0, \\
& q_{y 1}+q_{y 2}=0 .
\end{aligned}
$$

By eliminating $Q_{x 1}$ and $Q_{x 2}$ from the first three equations of (3) and (4), we can get

$$
\begin{gathered}
-\left(M_{y 1}+M_{y 2}\right)^{\prime \prime}+\frac{\left(N_{1}+N_{2}\right)}{R}=0, \\
\left(N_{1}+N_{2}\right)^{\prime}+\frac{\left(M_{y 1}+M_{y 2}\right)^{\prime}}{R}=0 .
\end{gathered}
$$

When there are no axial force and bending moment in $y$ direction of the I-beam caused by external forces, we can get

$$
\begin{gathered}
N_{1}=-N_{2}, \\
M_{y 1}=-M_{y 2} .
\end{gathered}
$$

\section{Equilibrium at the Interface}

At the interface, considering the deflections described in Figure 3, shear force $q_{z 2}$ described in Figure 2 can be written as

$$
\begin{aligned}
q_{z 2} & =K \Delta u=K\left(u_{2}-u_{1}+w^{\prime} b\right)=-N_{1}^{\prime}-\frac{M_{y 1}^{\prime}}{R} \\
& =N_{2}^{\prime}+\frac{M_{y 2}^{\prime}}{R},
\end{aligned}
$$

where $b=b_{1}+b_{2}$ and $\Delta u$ is the amount of the deflection at the interface in the tangential direction. So, the equilibrium at the interface in the tangential direction can be written as

$$
K\left(u_{2}-u_{1}+w^{\prime} b\right)+N_{1}^{\prime}+\frac{M_{y 1}^{\prime}}{R}=0 .
$$




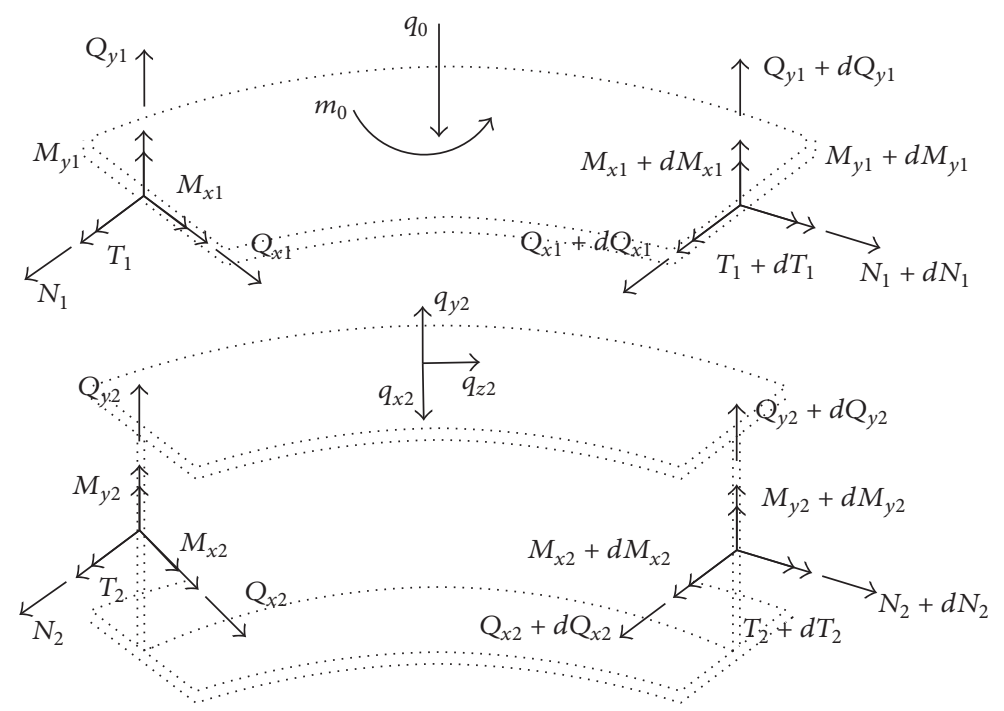

FIGURE 2: A microunit's force diagram of the horizontally composite curved I-beam.

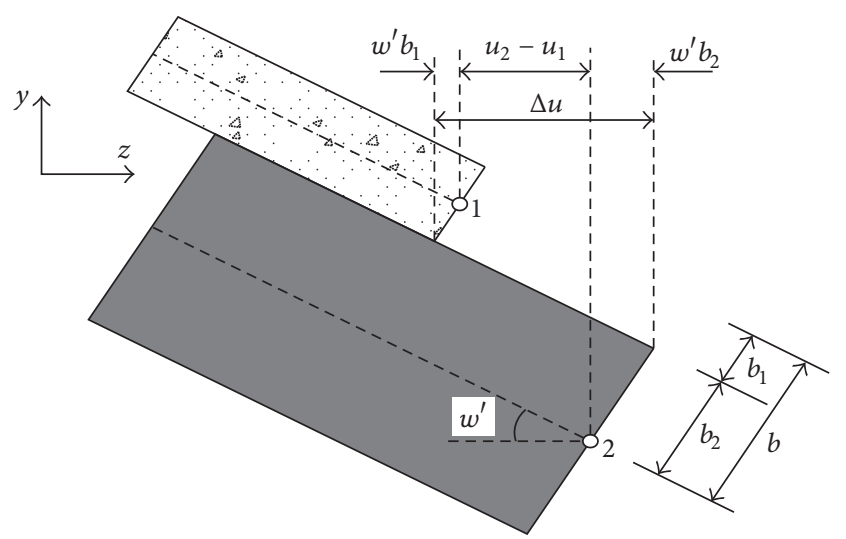

Figure 3: Deflections of differential elements for the beam in $y-z$ plane.

Considering deflection described in Figure 4, equilibrium at the interface in the radial direction can be written as

$$
v_{2}-v_{1}+\phi b=0 \text {. }
$$

In order to solve the problem under consideration, it is convenient to rearrange (9) and (10) as detailed in what follows. Firstly, taking the derivative of (9) one time with respect to $z$ component, then eliminating $v_{2}$ and $u_{2}$ by inserting the derivative equation and (10) into the first formula of (1), and at last using the first and second formulas of (2), one can obtain the following:

$$
\begin{aligned}
f_{z}= & \frac{E_{1} A_{1}}{K}\left(u_{1}^{\prime}-\frac{v_{1}}{R}\right)^{\prime \prime}+\frac{E_{1} I_{y 1}}{K R}\left(v_{1}^{\prime \prime}+\frac{u_{1}^{\prime}}{R}\right)^{\prime \prime} \\
& -S_{A} E_{1} A_{1}\left(u_{1}^{\prime}-\frac{v_{1}}{R}\right)+w^{\prime \prime} b-\frac{\phi b}{R}=0 .
\end{aligned}
$$

Analogously, taking the derivative of differential equation (9) one time and taking the derivative of (10) two times with

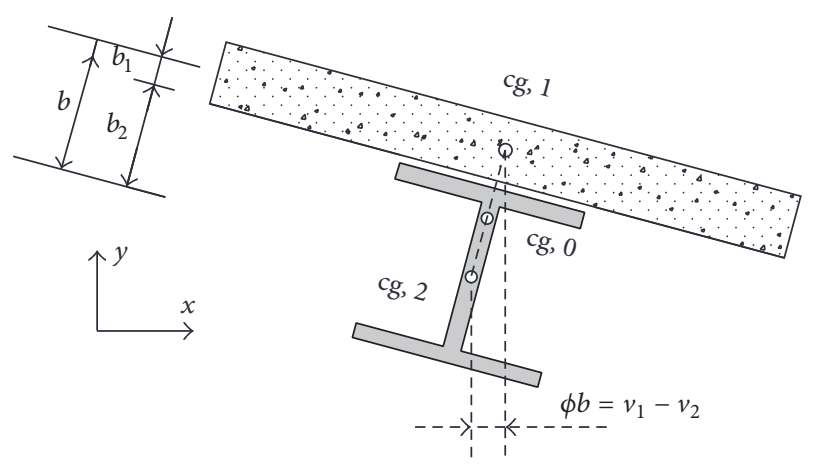

FIgURE 4: Deflection of the composite curved I-beam in $x-y$ plane.

respect to $z$ component firstly and then eliminating $v_{2}$ and $u_{2}$ by inserting these two derivative equations into the second formulas of (1), using (2), one can obtain the following:

$$
\begin{aligned}
f_{y}= & \frac{E_{1} A_{1}}{K R}\left(u_{1}^{\prime}-\frac{v_{1}}{R}\right)^{\prime \prime}+\frac{E_{1} I_{y 1}}{K R^{2}}\left(v_{1}^{\prime \prime}+\frac{u_{1}^{\prime}}{R}\right)^{\prime \prime} \\
& -S_{y} E_{1} I_{y 1}\left(v_{1}^{\prime \prime}+\frac{u_{1}^{\prime}}{R}\right)+\phi^{\prime \prime} b+\frac{w^{\prime \prime} b}{R}=0,
\end{aligned}
$$

where $S_{A}=1 / E_{2} A_{2}+1 / E_{1} A_{1}$ and $S_{y}=1 / E_{1} I_{y 1}+1 / E_{2} I_{y 2}$.

\section{Problem Formulation}

The governing differential equations of the beam will be derived by the principle of minimum potential energy. The potential energy of the beam takes the following form:

$$
\Pi=U_{M_{x}}+U_{T_{z}}+U_{M_{y}}+U_{a}+U_{s}-W
$$


$U_{M_{x}}$ is the bending strain energy due to the internal bending moments $M_{x 1}$ and $M_{x 2}$.

$$
\begin{aligned}
U_{M_{x}} & =\frac{1}{2} \int_{0}^{R \theta}\left(M_{x 1} k_{x 1}+M_{x 2} k_{x 2}\right) d z \\
& =\frac{1}{2} E I_{x} \int_{0}^{R \theta}\left(w^{\prime \prime}-\frac{\phi}{R}\right)^{2} d z
\end{aligned}
$$

where $E I_{x}=E_{1} I_{x 1}+E_{2} I_{x 2}$.

$U_{T}$ is the torsional strain energy due to the internal torsion moments $T_{1}$ and $T_{2}$.

$$
\begin{aligned}
U_{T} & =\frac{1}{2} \int_{0}^{R \theta}\left(T_{1} k_{z 1}+T_{2} k_{z 2}\right) d z \\
& =\frac{1}{2} G I_{T} \int_{0}^{R \theta}\left(\phi^{\prime}+\frac{w^{\prime}}{R}\right)^{2} d z
\end{aligned}
$$

where $G I_{T}=G_{1} I_{T 1}+G_{2} I_{T 2}$.

$U_{a}$ is the axial strain energy due to the internal axial forces $N_{1}$ and $N_{2}$.

$$
\begin{aligned}
U_{a} & =\frac{1}{2} \int_{0}^{R \theta}\left(N_{1} \varepsilon_{1}+N_{2} \varepsilon_{2}\right) d z \\
& =\frac{1}{2} \int_{0}^{R \theta} S_{A}\left[E_{1} A_{1}\left(u_{1}^{\prime}-\frac{v_{1}}{R}\right)\right]^{2} d z .
\end{aligned}
$$

$U_{M_{y}}$ is the bending strain energy due to the internal bending moments $M_{y 1}$ and $M_{y 2}$.

$$
\begin{aligned}
U_{M_{y}} & =\frac{1}{2} \int_{0}^{R \theta}\left(M_{y 1} k_{y 1}+M_{y 2} k_{y 2}\right) d z \\
& =\frac{1}{2} \int_{0}^{R \theta} S_{y}\left[E_{1} I_{y 1}\left(v_{1}^{\prime \prime}+\frac{u_{1}^{\prime \prime}}{R}\right)\right]^{2} d z .
\end{aligned}
$$

$U_{s}$ is the strain energy due to the connector deflections.

$$
\begin{aligned}
U_{s} & =\frac{1}{2} \int_{0}^{R \theta} q_{z 1} \cdot \Delta u d z=\frac{1}{2} \int_{0}^{R \theta} \frac{1}{K}\left(N_{1}^{\prime}+\frac{M_{y 1}^{\prime}}{R}\right)^{2} d z \\
& =\frac{1}{2} \int_{0}^{R \theta} \frac{1}{K}\left[E_{1} A_{1}\left(u_{1}^{\prime}-\frac{v_{1}}{R}\right)^{\prime}\right. \\
& \left.+\frac{E_{1} I_{y 1}}{R}\left(v_{1}^{\prime \prime}+\frac{u_{1}^{\prime}}{R}\right)^{\prime}\right]^{2} d z .
\end{aligned}
$$

$W$ is the potential energy due to the external loading.

$$
\begin{aligned}
W= & \int_{0}^{R \theta} m_{0} \phi d z+\int_{0}^{R \theta} q_{0} w d z+\left.\left(M_{x} w^{\prime}\right)\right|_{0} ^{R \theta} \\
& +\left.\left(Q_{y} w\right)\right|_{0} ^{R \theta}+\left.\left(T_{z} \phi\right)\right|_{0} ^{R \theta},
\end{aligned}
$$

where $M_{x}, Q_{y}$, and $T_{z}$ are the bending moment, shear force, and torsion moment of the beam, respectively. Using the Lagrange multiplier method, the principle of minimum potential energy in augmented form now may be written as

$$
\min \Pi^{*}=\Pi+\int_{0}^{R \theta}\left(\lambda_{z} \cdot f_{z}\right) d z+\int_{0}^{R \theta}\left(\lambda_{y} \cdot f_{y}\right) d z
$$

where the parameters $\lambda_{z}$ and $\lambda_{y}$ are the Lagrange multipliers and $f_{z}$ and $f_{y}$ are the equilibrium conditions at the interface corresponding to (11) and (12), respectively. In (20), $\phi, w, v_{1}$, $u_{1}, \lambda_{z}$, and $\lambda_{z}$ are all independent variables. The variation of $\Pi^{*}$ is

$$
\begin{aligned}
& \delta \Pi^{*}=\int_{0}^{R \theta} \Gamma_{1} \delta w d z+\int_{0}^{R \theta} \Gamma_{2} \delta \phi d z+\int_{0}^{R \theta} \Gamma_{3} \delta \lambda_{z} d z \\
& +\int_{0}^{R \theta} \Gamma_{4} \delta \lambda_{y} d z+\int_{0}^{R \theta} \Gamma_{5} \delta v_{1} d z+\int_{0}^{R \theta} \Gamma_{6} \delta u_{1} d z \\
& +\left.H_{1} \delta w\right|_{0} ^{R \theta}+\left.H_{2} \delta w^{\prime}\right|_{0} ^{R \theta}+\left.H_{3} \delta \phi\right|_{0} ^{R \theta}+\left.H_{4} \delta \phi^{\prime}\right|_{0} ^{R \theta} \\
& +\left.H_{5} \delta u_{1}\right|_{0} ^{R \theta}+\left.H_{6} \delta u_{1}^{\prime}\right|_{0} ^{R \theta}+\left.H_{7} \delta v_{1}\right|_{0} ^{R \theta}+\left.H_{8} \delta v_{1}^{\prime}\right|_{0} ^{R \theta} \\
& +\left.H_{9} \delta v_{1}^{\prime \prime}\right|_{0} ^{R \theta} \\
& +\left.H_{10} \delta[\underbrace{\frac{E_{1} I_{y 1}}{R K}\left(v_{1}^{\prime \prime}+\frac{u_{1}^{\prime}}{R}\right)^{\prime}+\frac{E_{1} A_{1}}{K}\left(u_{1}^{\prime}-\frac{v_{1}^{\prime}}{R}\right)^{\prime}}_{\Delta u}]\right|_{0} ^{R \theta},
\end{aligned}
$$

where $\Gamma_{i}(i=1 \sim 6)$ and $H_{i}(i=1 \sim 10)$ are calculated from the variation of $\Pi^{*}$, which are given in Appendix A. Each term in (21) must be identically zero. It makes $\Gamma_{5}=0, \Gamma_{6}=0, H_{5}=0$, $H_{6}=0, H_{7}=0, H_{8}=0$, and $H_{9}=0$; that is, the undermined Lagrange multipliers $\lambda_{z}$ and $\lambda_{y}$ are

$$
\begin{aligned}
& \lambda_{z}=E_{1} A_{1}\left(u_{1}^{\prime}-\frac{v_{1}}{R}\right)=N_{1}, \\
& \lambda_{y}=E_{1} I_{y 1}\left(v_{1}^{\prime \prime}+\frac{u_{1}^{\prime}}{R}\right)=M_{y 1} .
\end{aligned}
$$

Equation (22) notes that the Lagrange multipliers and the deflections $\left(u_{1}\right.$ and $\left.v_{1}\right)$ are related. So, there will be four rather than six independent variables in this problem. We can take $\phi$, $w, \lambda_{z}$, and $\lambda_{y}$ as independent variables. The rest of governing equations are $\Gamma_{1}=0, \Gamma_{2}=0, \Gamma_{3}=0$, and $\Gamma_{4}=0$, which can be rearranged and rendered in terms of matrix form, as shown below. 


$$
\left[\begin{array}{cccc}
E I_{x} \frac{d^{4}}{d z^{4}}-\frac{G I_{T}}{R^{2}} \frac{d^{2}}{d z^{2}} & -\frac{E I_{x}+G I_{T}}{R} \frac{d^{2}}{d z^{2}} & b \frac{d^{2}}{d z^{2}} & \frac{b}{R} \frac{d^{2}}{d z^{2}} \\
-\frac{E I_{x}+G I_{T}}{R} \frac{d^{2}}{d z^{2}} & -G I_{d} \frac{d^{2}}{d z^{2}}+\frac{E I_{x}}{R^{2}} & -\frac{b}{R} & b \frac{d^{2}}{d z^{2}} \\
b \frac{d^{2}}{d z^{2}} & -\frac{b}{R} & \frac{1}{K} \frac{d^{2}}{d z^{2}}-S_{A} & \frac{1}{R K} \frac{d^{2}}{d z^{2}} \\
\frac{b}{R} \frac{d^{2}}{d z^{2}} & b \frac{d^{2}}{d z^{2}} & \frac{1}{R K} \frac{d^{2}}{d z^{2}} & \frac{1}{R^{2} K} \frac{d^{2}}{d z^{2}}-S_{y}
\end{array}\right]\left(\begin{array}{c}
w \\
\phi \\
\lambda_{z} \\
\lambda_{y}
\end{array}\right)=\left(\begin{array}{c}
q_{0} \\
m_{0} \\
0 \\
0
\end{array}\right)
$$

We can get the pertaining boundary conditions:

$$
\begin{aligned}
& {\left[-E I_{x}\left(w^{\prime \prime \prime}-\frac{\phi^{\prime}}{R}\right)-b \lambda_{z}^{\prime}-\frac{b}{R} \lambda_{y}^{\prime}+G I_{T}\left(\frac{\phi^{\prime}}{R}+\frac{w^{\prime}}{R^{2}}\right)\right.} \\
& \left.-Q_{y}\right]\left.\delta w\right|_{0} ^{R \theta}=0, \\
& {\left.\left[E I_{x}\left(w^{\prime \prime}-\frac{\phi}{R}\right)+b \lambda_{z}+\frac{b}{R} \lambda_{y}-M_{x}\right] \delta w^{\prime}\right|_{0} ^{R \theta}=0,} \\
& {\left.\left[G I_{T}\left(\phi^{\prime}+\frac{w^{\prime}}{R}\right)-b \lambda_{y}^{\prime}-T_{z}\right] \delta \phi\right|_{0} ^{R \theta}=0,} \\
& \left.\left(b \lambda_{y}\right) \delta \phi^{\prime}\right|_{0} ^{R \theta}=0, \\
& \left.\left(\lambda_{z}+\frac{\lambda_{y}}{R}\right) \delta(\Delta u)\right|_{0} ^{R \theta}=0 .
\end{aligned}
$$

It is evident that (23) is tenth-order ordinary differential equation. We have ten boundary conditions for the beam, that is, five boundary conditions for each end. For the boundary conditions (see (24)) to hold, the following alternatives at each end shown as in Table 1 are conducted.

\section{Analytical Solution by Trigonometric Series}

In this section, a closed form solution of the simply supported horizontally composite curved I-beam is obtained. The deflection functions and the Lagrange multiplier functions are expressed as undetermined coefficients and known trigonometric series to satisfy the governing equations and the rigid torsion constraints at each end. The deflection and the Lagrange multiplier are assumed to be the following form:

$$
\begin{gathered}
w=\sum_{i=1}^{n} w_{i} \sin \left(\frac{i \pi z}{L}\right), \\
\phi=\sum_{i=1}^{n} \phi_{i} \sin \left(\frac{i \pi z}{L}\right), \\
\lambda_{z}=\sum_{i=1}^{n} \lambda_{z i} \sin \left(\frac{i \pi z}{L}\right), \\
\lambda_{y}=\sum_{i=1}^{n} \lambda_{y i} \sin \left(\frac{i \pi z}{L}\right),
\end{gathered}
$$

where $w_{i}, \phi_{i}, \lambda_{z i}$, and $\lambda_{y i}$ are unknown Fourier coefficients to be determined for each $i(i=1, \ldots, n)$ and $L$ is span length. The applied distributed load $q_{0}$ and $m_{0}$ are expanded in single trigonometric series as

$$
\begin{aligned}
& q_{0}=\sum_{i=1}^{n} q_{i} \sin \left(\frac{i \pi z}{L}\right), \\
& m_{0}=\sum_{i=1}^{n} m_{i} \sin \left(\frac{i \pi z}{L}\right),
\end{aligned}
$$

where $q_{i}$ and $m_{i}$ are the Fourier coefficients. Multiplying both sides of (26) by each trigonometric series and then integrating them over $(0, L)$, finally, the trigonometric coefficients $q_{i}$ and $m_{i}$ can be readily determined with the orthogonality properties. Substituting (25)-(26) into (23) and solving (23), the unknown parameters $w_{i}, \phi_{i}, \lambda_{z i}$, and $\lambda_{y i}$ can be determined. The unknown Fourier coefficients are given as follows:

$$
\begin{aligned}
& w_{i}=q_{i} \frac{\gamma_{q 1}+\gamma_{q 2}}{\gamma}+m_{i} \frac{\gamma_{m 1}}{\gamma}, \\
& \phi_{i}=q_{i} \frac{\gamma_{q 3}}{\gamma}+m_{i} \frac{\gamma_{m 2}+\gamma_{m 3}}{\gamma}, \\
& \lambda_{z i}=q_{i} \frac{\gamma_{q 4}}{\gamma}+m_{i} \frac{\gamma_{m 4}}{\gamma}, \\
& \lambda_{y i}=q_{i} \frac{\gamma_{q 5}}{\gamma}+m_{i} \frac{\gamma_{m 5}}{\gamma},
\end{aligned}
$$

where $\gamma, \gamma_{q i}$, and $\gamma_{m i}(i=1, \ldots, 5)$ are the relevant coefficients which are given in Appendix B.

\section{Numerical Example}

A steel-concrete composite curved I-beam calculated by Thevendran et al. [27] is taken as a numerical example in order to show the accuracy and reliability of the present trigonometric solution of the beam. The beam is simply supported at both ends as shown in Figure 1. And the beam is subjected to $F=150 \mathrm{KN}$ vertical load at the midspan section. The material properties and dimensions of the curved I-beam (SP4 beam) are shown in Table 2.

The finite element software ANSYS is used to model the described structure (Figure 5). In the FEM model, both the 
TABLE 1: Common support conditions.

\begin{tabular}{|c|c|}
\hline Type & The boundary conditions \\
\hline \multirow{5}{*}{ Free end } & $Q_{y}=0$ \\
\hline & $M_{x}=0$ \\
\hline & $T_{z}=0$ \\
\hline & $\lambda_{z}=0$ \\
\hline & $\lambda_{y}=0$ \\
\hline \multirow{5}{*}{ Fixed end } & $w=0$ \\
\hline & $\phi=0$ \\
\hline & $w^{\prime}=0$ \\
\hline & $\phi^{\prime}=0$ \\
\hline & $\Delta u=0$ \\
\hline \multirow{5}{*}{$\begin{array}{l}\text { Rigid torsion constraints } \\
\text { end }\end{array}$} & $w=0$ \\
\hline & $\phi=0$ \\
\hline & $M_{x}=0$ \\
\hline & $\lambda_{z}=0$ \\
\hline & $\lambda_{y}=0$ \\
\hline \multirow{5}{*}{ Hinged end } & $w=0$ \\
\hline & $T_{z}=0$ \\
\hline & $M_{x}=0$ \\
\hline & $\lambda_{z}=0$ \\
\hline & $\lambda_{y}=0$ \\
\hline
\end{tabular}

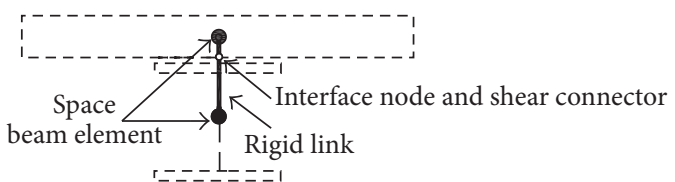

FIGURE 5: Finite element model diagram of the composite curved I-beam.

concrete slab and the steel I-girder are modeled as space beam elements and the connection between the slab and I-girder is simulated by multiple-point constraints (MPC) which are modeled by two rigid links connected through interface nodes between the slab and I-girder. The spring elements are used in the tangential direction to allow for the possibility of movement. Coupling degrees of freedom $w$ are used to prevent the uplifting issue.

The vertical deflection $w$, the tangential deflection $u$, the radial deflection $v$, and the torsional deflection $\phi$ are restrained to satisfy the simply supported constraints at both ends. Although the BEAM4 element in ANSYS cannot consider the warping effect, the element meets the theory of this paper quite well. So, 120 BEAM4 elements are selected as the spatial beam elements. The element of MPC 184 with the number of 122 is modeled as the multiple-point constraints element. In addition, the element of COMBIN 14 with the number of 61 is used when tangential slip is considered.

For the full interaction case, the slip parameters are taken as $K=10^{10} \mathrm{~N} / \mathrm{m}^{2}$. Figure 6 shows the vertical deflection $w$ based on the FEM, the solution calculated by this paper, and Thevendran et al. experimental results, respectively. For

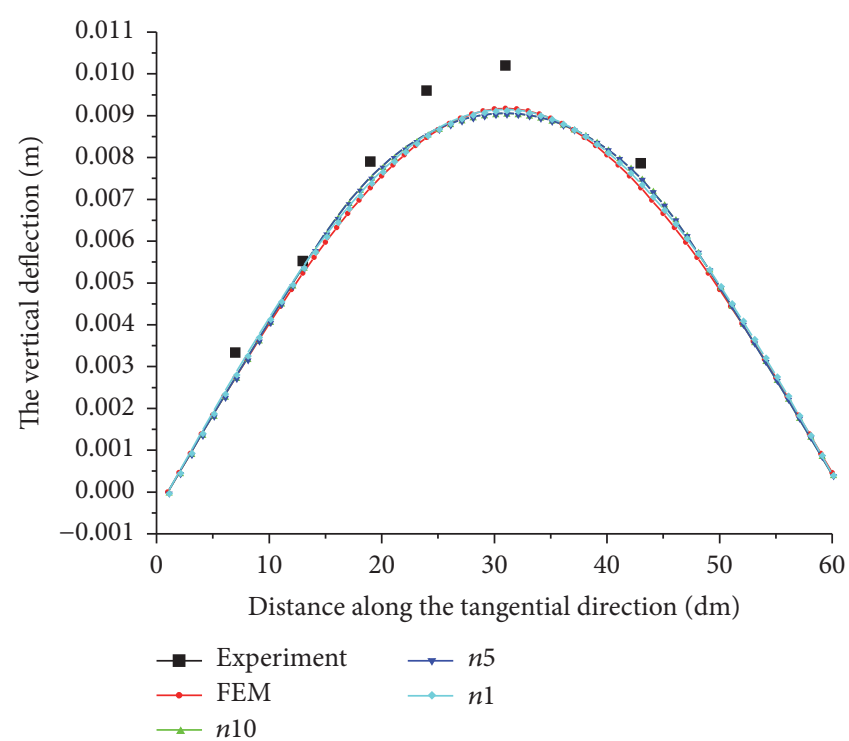

Figure 6: Vertical deflection of the beam.

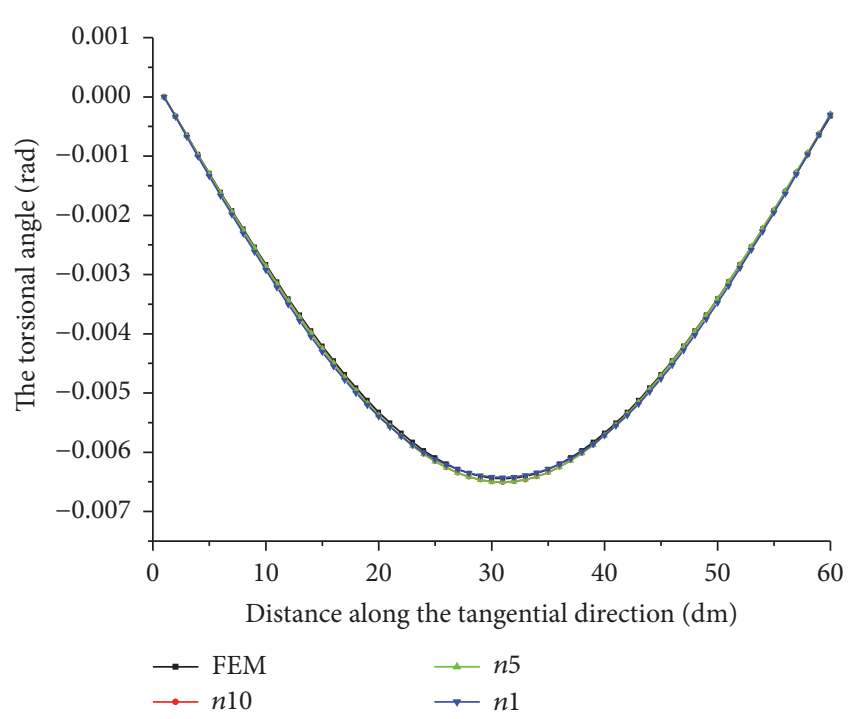

FIGURE 7: Torsional angle of the beam.

this paper solution, the number of Fourier coefficients $n$ (in (25)) can be chosen as large as we can to achieve a required accuracy. As an illustration of convergence of the results, we show the results from this paper by taking the number $n$ as 1 , 5, and 10 terms, respectively. It can be seen in Figure 6 that the vertical deflections results solved from this paper and from Thevendran et al. experiment are in reasonable agreement (the difference is within 12\%), and the solved results from this paper and from FEM are in good agreement.

Considering only vertical deflections are available from the experiments of Thevendran et al., the other results of the solution calculated by this paper and by the FEM are compared in Figures 7-12. The results are the torsional angle $\phi$, the bending moment $M_{y 1}\left(M_{y 1}=\lambda_{y}\right)$, the axial force $N_{1}$ $\left(N_{1}=\lambda_{z}\right)$, the bending moment $M_{x}$, the shear force $Q_{y}$, and the torsion moment $T_{z}$, respectively. 
TABLE 2: Material properties and dimensions of the curved I-beam.

\begin{tabular}{lccccccc}
\hline & $\begin{array}{c}\text { Young's modulus } \\
(\mathrm{GPa})\end{array}$ & $\begin{array}{c}\text { Poisson's } \\
\text { ratio }\end{array}$ & $\begin{array}{c}\text { Density } \\
\left(\mathrm{kg} / \mathrm{m}^{3}\right)\end{array}$ & $\begin{array}{c}\text { Width } \\
(\mathrm{mm})\end{array}$ & $\begin{array}{c}\text { Thickness } \\
(\mathrm{mm})\end{array}$ & $\begin{array}{c}\text { Central } \\
\text { angle }\end{array}$ & $\begin{array}{c}\text { Radius of curvature } \\
(\mathrm{m})\end{array}$ \\
\hline Steel girder & 206 & 0.3 & 7850 & $\begin{array}{c}\text { Flange: } 332 \\
\text { Web: } 172\end{array}$ & $\begin{array}{c}\text { Flange: } 13 \\
\text { Web: } 8\end{array}$ & $\theta=14.3^{\circ}$ & 24 \\
Concrete slab & 26 & 0.27 & 2400 & 1500 & 100 & \\
\hline
\end{tabular}

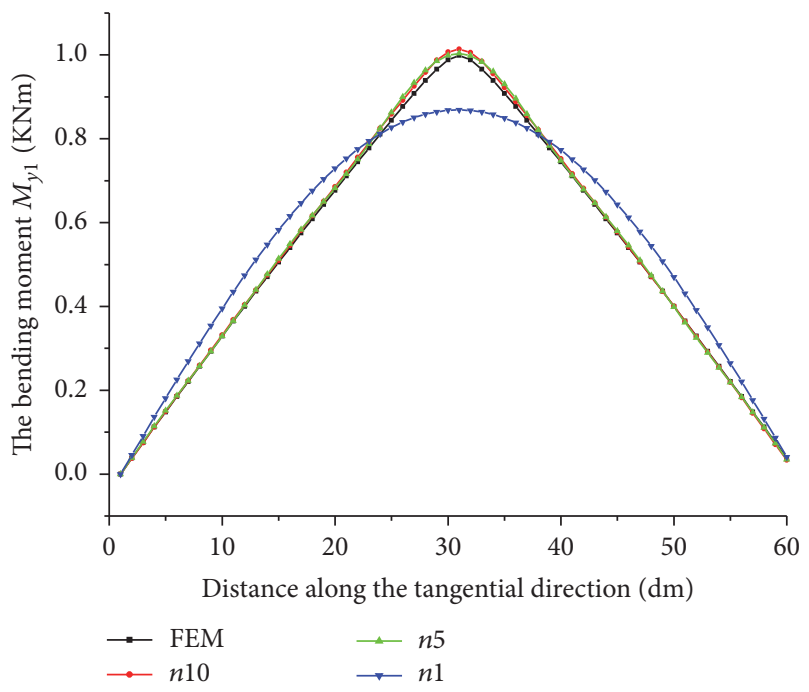

FIGURE 8: Bending moment $M_{y 1}$ of the beam.

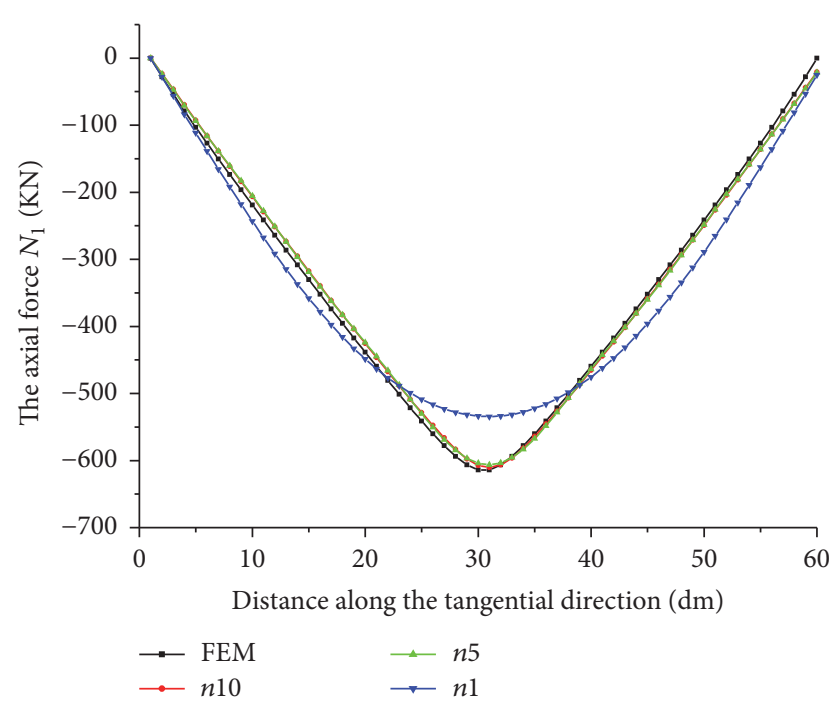

FIgURE 9: Axial force $N_{1}$ of the beam.

It can be seen from Figures 7-12 that the results solved by this paper can be quickly convergent, and one can get very good results by taking more than 5 terms. When the stiffness of the shear connectors is changed, the vertical deflection and torsional angle at midspan section are shown in Figures 13 and 14, respectively. In Figure 13, it can be seen that the vertical deflections converge to the minimum when the slip parameter $K$ is greater than $10^{10} \mathrm{~N} / \mathrm{m}^{2}$. Moreover, the

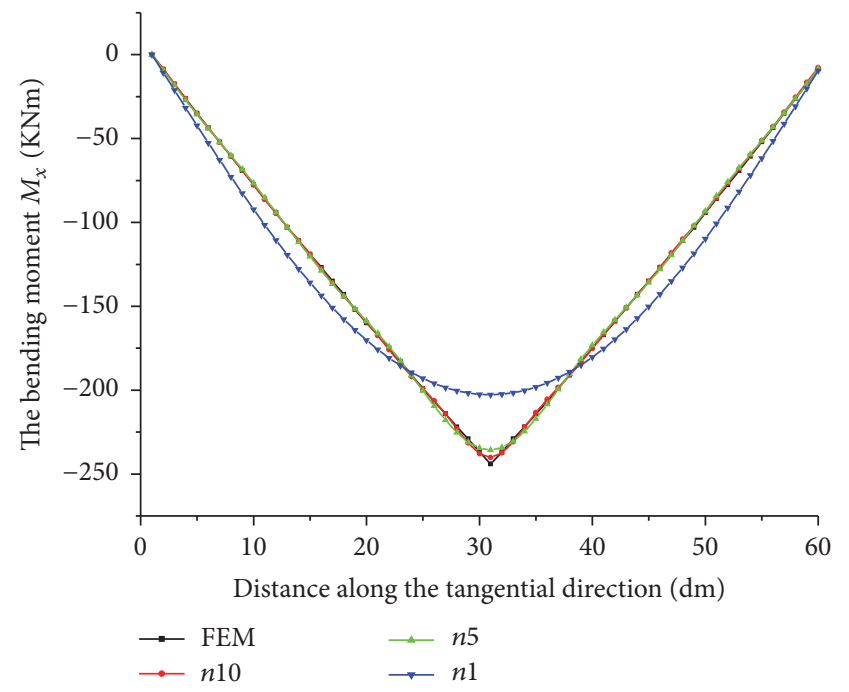

FIgURE 10: Bending moment $M_{x}$ of the beam.

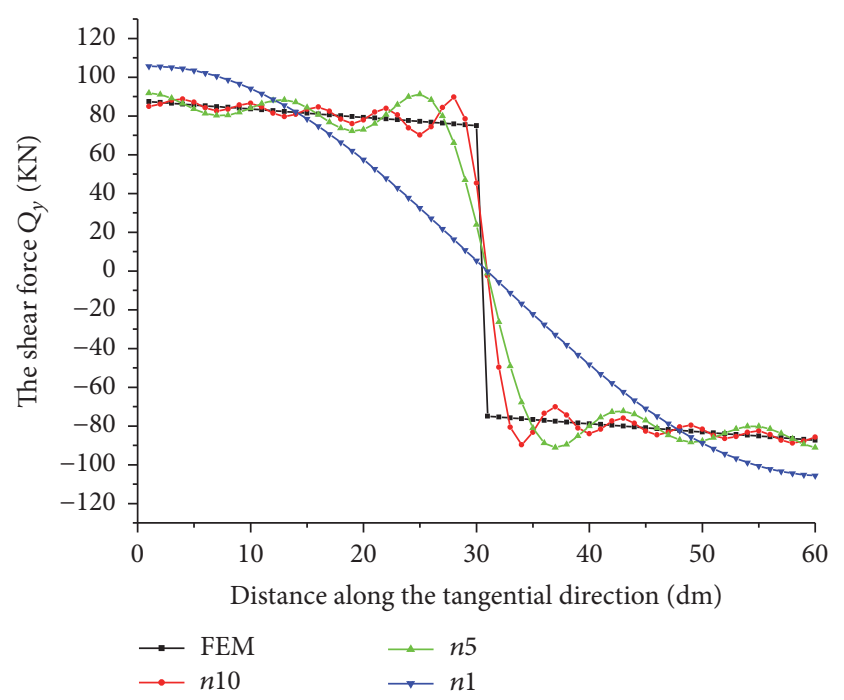

FIGURE 11: Shear force $Q_{y}$ of the beam.

changes with slip parameter $K$ indicate the shear connecter's stiffness in experimental model of Thevendran et al. with the range from $10^{9} \mathrm{~N} / \mathrm{m}^{2}$ to $10^{10} \mathrm{~N} / \mathrm{m}^{2}$. As it can be seen from Figures 13 and 14, the performance of the curved composite I-beam becomes significantly rigid when the shear connecter's stiffness is increased from $10^{7}$ to $10^{9} \mathrm{~N} / \mathrm{m}^{2}$. The reduction of shear connectors' stiffness between layers has a significant effect on the vertical deflection and torsional angle at midspan section. 


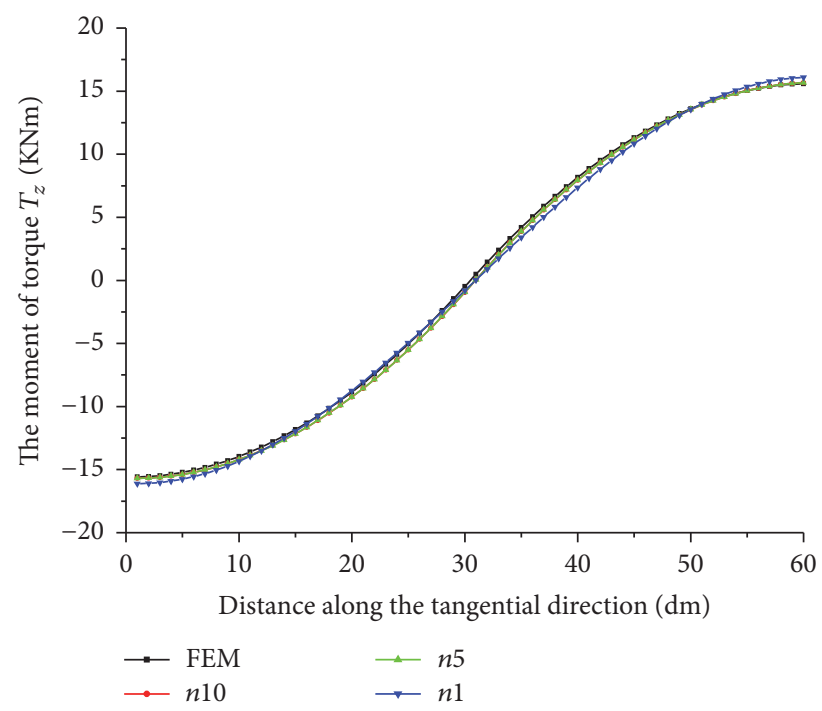

Figure 12: Torsion moment $T_{z}$ of the beam.

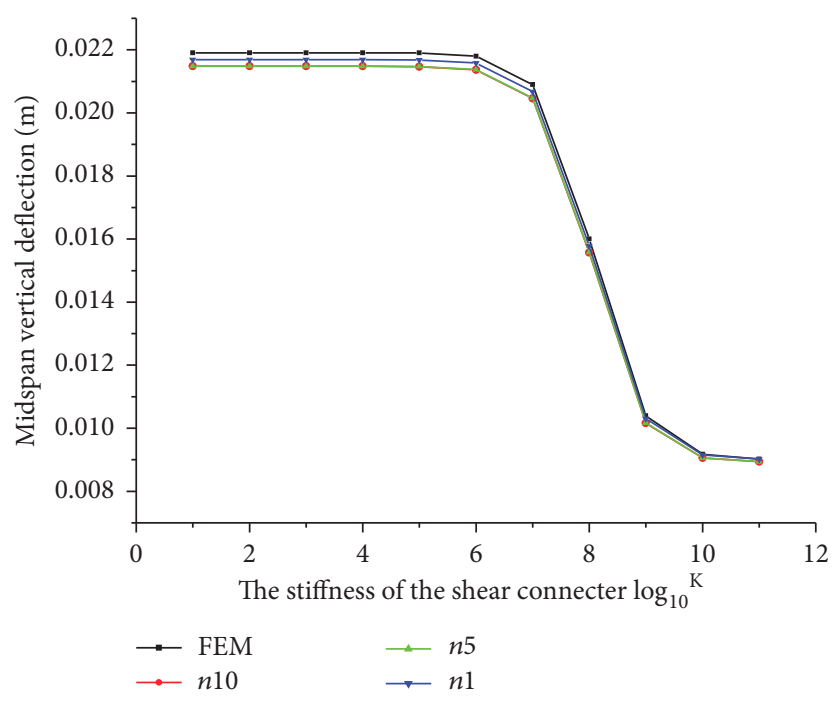

FIGURE 13: Vertical deflection at midspan section when the stiffness of the shear connecter is changed.

The inaccuracy of the vertical deflection and torsional angle between analytical solutions in this paper and the FEM results in Figures 6-14 is small and reasonable. Thus, the model created in this paper can be applied sufficiently for practical purposes.

\section{Conclusions}

In this paper, an analytical solution has been developed and presented for the simply supported horizontally composite curved I-beam. It is primarily used to solve a static problem of a two-layered composite curved beam with flexible shear connection in the tangential direction. The trigonometric series are adopted in solution expression in terms of span coordinate. Both governing equations and boundary conditions are obtained by using the Vlasov curved beam

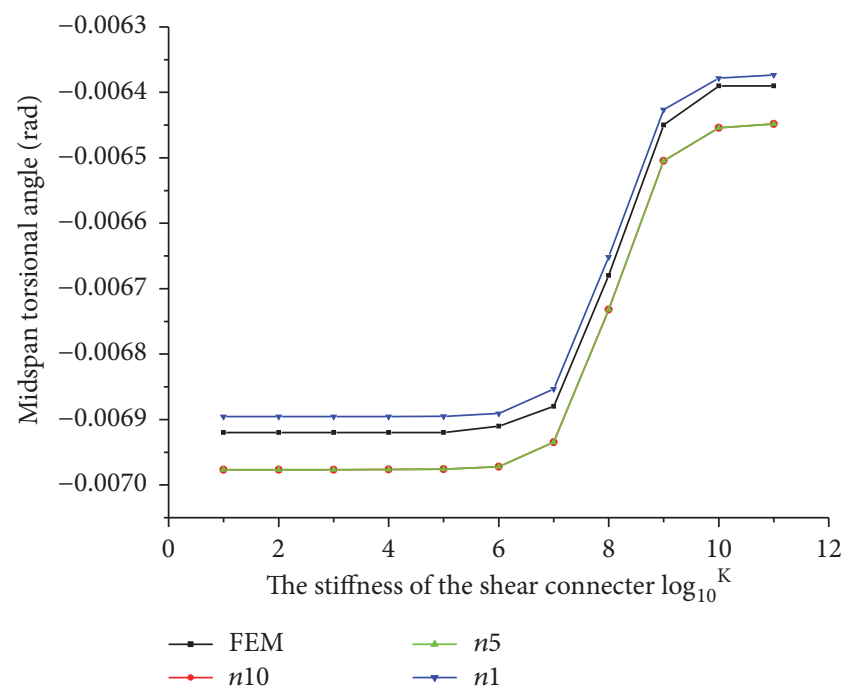

FIGURE 14: Torsional angle at midspan when the stiffness of the shear connecter is changed.

theory and the principle of minimum potential energy. The accuracy of calculation results based on the theory presented in this paper is verified by comparing with the FEM and the Thevendran et al. experimental results. Therefore, the analytical expression and model established in this paper possess certain actual engineering significance.

\section{Appendix}

A. Component of $\Gamma_{i}(i=1 \sim 6)$ and $H_{i}(i=1 \sim 10)$

Consider

$$
\begin{aligned}
\Gamma_{1}= & E I_{x} w^{\prime \prime \prime \prime}-G I_{T} \frac{w^{\prime \prime}}{R^{2}}-\frac{E I_{x}+G I_{T}}{R} \phi^{\prime \prime}+b \lambda_{z}^{\prime \prime} \\
& +\frac{b \lambda_{y}^{\prime \prime}}{R}-q_{0}, \\
\Gamma_{2}= & -\frac{E I_{x}+G I_{T}}{R} w^{\prime \prime}-G I_{d} \phi^{\prime \prime}+\frac{E I_{x}}{R^{2}} \phi-\frac{b \lambda_{z}}{R}+b \lambda_{y}^{\prime \prime} \\
& -m_{0}, \\
\Gamma_{3}= & {\left[E_{1} A_{1}\left(u_{1}^{\prime}-\frac{v_{1}}{R}\right)^{\prime \prime}+\frac{E_{1} I_{y 1}}{R}\left(v_{1}^{\prime \prime}+\frac{u_{1}^{\prime}}{R}\right)^{\prime \prime}\right] \frac{1}{K} } \\
& -S_{A} E_{1} A_{1}\left(u_{1}^{\prime}-\frac{v_{1}}{R}\right)+w^{\prime \prime} b-\frac{\phi b}{R}, \\
\Gamma_{4}= & {\left[E_{1} A_{1}\left(u_{1}^{\prime}-\frac{v_{1}}{R}\right)^{\prime \prime}+\frac{E_{1} I_{y 1}}{R}\left(v_{1}^{\prime \prime}+\frac{u_{1}^{\prime}}{R}\right)^{\prime \prime}\right] \frac{1}{R K} } \\
& -S_{y} E_{1} I_{y 1}\left(v_{1}^{\prime \prime}+\frac{u_{1}^{\prime}}{R}\right)+\phi^{\prime \prime} b+\frac{w^{\prime \prime} b}{R}, \\
\Gamma_{5}= & E_{1} I_{y 1} S_{y}\left[E_{1} I_{y 1}\left(v_{1}^{\prime \prime}+\frac{u_{1}^{\prime}}{R}\right)-\lambda_{y}\right]^{\prime \prime}-E_{1} A_{1} S_{A}
\end{aligned}
$$




$$
\begin{aligned}
& \cdot \frac{1}{R}\left[E_{1} A_{1}\left(u_{1}^{\prime}-\frac{v_{1}}{R}\right)-\lambda_{z}\right] \\
+ & \frac{E_{1} A_{1}}{K R}\left[E_{1} A_{1}\left(u_{1}^{\prime}-\frac{v_{1}}{R}\right)+\frac{E_{1} I_{y 1}}{R}\left(v_{1}^{\prime \prime}+\frac{u_{1}^{\prime}}{R}\right)\right. \\
& \left.-\lambda_{z}-\frac{\lambda_{y}}{R}\right]^{\prime \prime}-\frac{E_{1} I_{y 1}}{K R}\left[E_{1} A_{1}\left(u_{1}^{\prime}-\frac{v_{1}}{R}\right)\right. \\
& \left.+\frac{E_{1} I_{y 1}}{R}\left(v_{1}^{\prime \prime}+\frac{u_{1}^{\prime}}{R}\right)-\lambda_{z}-\frac{\lambda_{y}}{R}\right]^{\prime \prime \prime \prime}, \\
\Gamma_{6}= & \frac{1}{K}\left[E_{1} A_{1}\left(u_{1}^{\prime}-\frac{v_{1}}{R}\right)+\frac{E_{1} I_{y 1}}{R}\left(v_{1}^{\prime \prime}+\frac{u_{1}^{\prime}}{R}\right)-\lambda_{z}\right. \\
- & \left.\frac{\lambda_{y}}{R}\right]^{\prime \prime \prime}\left(E_{1} A_{1}+\frac{E_{1} I_{y 1}}{R^{2}}\right) \\
- & E_{1} A_{1} S_{A}\left[E_{1} A_{1}\left(u_{1}^{\prime}-\frac{v_{1}}{R}\right)-\lambda_{z}\right]^{\prime} \\
& -\frac{S_{y} E_{1} I_{y 1}}{R}\left[E_{1} I_{y 1}\left(v_{1}^{\prime \prime}+\frac{u_{1}^{\prime}}{R}\right)-\lambda_{y}\right]^{\prime}, \\
H_{5}= & E_{1} A_{1} S_{A}\left[E_{1} A_{1}\left(u_{1}^{\prime}-\frac{v_{1}}{R}\right)-\lambda_{z} A_{1}\left(u_{1}^{\prime}-\frac{v_{1}}{R}\right)+\frac{E_{1} I_{y 1}}{R}\left(v_{1}^{\prime \prime}+\frac{u_{1}^{\prime}}{R}\right)-\lambda_{z}\right. \\
+ & S_{y} E_{1} I_{y 1}\left[E_{1} I_{y 1}\left(v_{1}^{\prime \prime}+\frac{u_{1}^{\prime}}{R}\right)-\lambda_{y}\right] \\
H_{1}= & -E I_{x}\left(w^{\prime \prime \prime}-\frac{\phi^{\prime}}{R}\right)-b \lambda_{z}^{\prime}-\frac{b}{R} \lambda_{y}^{\prime}+G I_{T}\left(\frac{\phi^{\prime}}{R}\right. \\
+ & \left.\frac{w^{\prime}}{R^{2}}\right)-Q_{y}, \\
H_{2}= & E I_{x}\left(w^{\prime \prime}-\frac{\phi}{R}\right)+b \lambda_{z}+\frac{b}{R} \lambda_{y}-M_{x}, \\
H_{y}, & \\
&
\end{aligned}
$$

$$
\begin{aligned}
& \left.-\frac{\lambda_{y}}{R}\right]^{\prime \prime}\left(E_{1} A_{1}+\frac{E_{1} I_{y 1}}{R^{2}}\right), \\
H_{6} & =\frac{1}{K}\left[E_{1} A_{1}\left(u_{1}^{\prime}-\frac{v_{1}}{R}\right)+\frac{E_{1} I_{y 1}}{R}\left(v_{1}^{\prime \prime}+\frac{u_{1}^{\prime}}{R}\right)\right. \\
& \left.-\lambda_{z}-\frac{\lambda_{y}}{R}\right]^{\prime}\left(E_{1} A_{1}+\frac{E_{1} I_{y 1}}{R^{2}}\right), \\
H_{7} & =-E_{1} I_{y 1} S_{y}\left[E_{1} I_{y 1}\left(v_{1}^{\prime \prime}+\frac{u_{1}^{\prime}}{R}\right)-\lambda_{y}\right]^{\prime} \\
& -\frac{E_{1} A_{1}}{K R}\left[E_{1} A_{1}\left(u_{1}^{\prime}-\frac{v_{1}}{R}\right)^{\prime}+\frac{E_{1} I_{y 1}}{R}\left(v_{1}^{\prime \prime}+\frac{u_{1}^{\prime}}{R}\right)^{\prime}\right. \\
& \left.-\lambda_{z}^{\prime}-\frac{\lambda_{y}^{\prime}}{R}\right]+\frac{E_{1} I_{y 1}}{K R}\left[E_{1} A_{1}\left(u_{1}^{\prime}-\frac{v_{1}}{R}\right)^{\prime}\right. \\
& \left.+\frac{E_{1} I_{y 1}}{R}\left(v_{1}^{\prime \prime}+\frac{u_{1}^{\prime}}{R}\right)^{\prime}-\lambda_{z}^{\prime}-\frac{\lambda_{y}^{\prime}}{R}\right]^{\prime \prime}, \\
H_{10} & =\lambda_{z}+\frac{\lambda_{y}}{R} . \\
H_{8}= & E_{1} I_{y 1} S_{y}\left[E_{1} I_{y 1}\left(v_{1}^{\prime \prime}+\frac{u_{1}^{\prime}}{R}\right)-\lambda_{y}\right] \\
& -\frac{E_{1} I_{y 1}}{K R}\left[E_{1} A_{1} I_{1}\left(u_{1}^{\prime}-\frac{v_{1}}{R}\right)^{\prime}+\frac{E_{1} I_{y 1}}{R}\left(E_{1} A_{1}^{\prime \prime}+\frac{u_{1}^{\prime}}{R}\right)^{\prime}\right. \\
&
\end{aligned}
$$

B. Component of $\gamma, \gamma_{q i}$, and $\gamma_{m i}(i=1 \sim 5)$ Consider

$$
\begin{aligned}
\gamma & =\left(K L^{2} R^{2}\left(b^{2} i^{2} \pi^{2}+L^{2} E I_{T} S_{y}\right)\left(b^{2}+E I_{x} S_{A}\right)+i^{2} \pi^{2}\left(b^{2} i^{2} \pi^{2} R^{2} E I_{x}+L^{2} E I_{T}\left(b^{2}+E I_{x}\left(R^{2} S_{y}+S_{A}\right)\right)\right)\right), \\
\gamma_{q 1} & =\frac{L^{4} R^{2}\left(b^{2}\left(L^{2}-i^{2} \pi^{2} R^{2}\right)^{2}+L^{2}\left(b^{2} i^{2} K \pi^{2} R^{4}+i^{2} \pi^{2} R^{2} E I_{T}+L^{2} E I_{x}\right) S_{A}\right)}{\left(L^{2}-i^{2} \pi^{2} R^{2}\right)^{2}}, \\
\gamma_{q 2} & =\frac{L^{6} R^{4} S_{y}\left(b^{2} K L^{4}+i^{2} \pi^{2} R^{2} E I_{T}\left(i^{2} \pi^{2}+K L^{2} S_{A}\right)+E I_{x}\left(i^{2} L^{2} \pi^{2}+K L^{4} S_{A}\right)\right)}{\left(i L^{2} \pi-i^{3} \pi^{3} R^{2}\right)^{2}},
\end{aligned}
$$




$$
\begin{aligned}
& \gamma_{q 3}=\frac{-L^{6} R^{3}\left(i^{2} \pi^{2}\left(b^{2} K R^{2}+E I_{T}+E I_{x}\right) S_{A}+R^{2} S_{y}\left(i^{2} \pi^{2}\left(E I_{T}+E I_{x}\right)+K L^{2}\left(b^{2}+\left(E I_{T}+E I_{x}\right) S_{A}\right)\right)\right)}{\left(L^{2}-i^{2} \pi^{2} R^{2}\right)^{2}}, \\
& \gamma_{q 4}=\frac{b L^{4} R^{2}\left(i^{2} \pi^{2}\left(b^{2} K R^{2}+E I_{x}\right)+E I_{T}\left(i^{2} \pi^{2}+K L^{2} R^{2} S_{y}\right)\right)}{L^{2}-i^{2} \pi^{2} R^{2}}, \\
& \gamma_{q 5}=\frac{b L^{4} R^{3}\left(i^{2} \pi^{2}\left(E I_{T}+E I_{x}\right)+K L^{2}\left(b^{2}+E I_{x} S_{A}\right)\right)}{\left(-L^{2}+i^{2} \pi^{2} R^{2}\right)}, \\
& \gamma_{m 1}=\frac{-L^{6} R^{3}\left(i^{2} \pi^{2}\left(b^{2} K R^{2}+E I_{T}+E I_{x}\right) S_{A}+R^{2} S_{y}\left(i^{2} \pi^{2}\left(E I_{T}+E I_{x}\right)+K L^{2}\left(b^{2}+\left(E I_{T}+E I_{x}\right) S_{A}\right)\right)\right)}{\left(L^{2}-i^{2} \pi^{2} R^{2}\right)^{2}}, \\
& \gamma_{m 2}=\frac{i^{2} L^{4} \pi^{2} R^{2}\left(L^{2} E I_{T}+R^{2}\left(b^{2} K L^{2}+i^{2} \pi^{2} E I_{x}\right)\right) S_{A}}{\left(L^{2}-i^{2} \pi^{2} R^{2}\right)^{2}}, \\
& \gamma_{m 3}=\frac{L^{4} R^{4} S_{y}\left(E I_{T}\left(i^{2} L^{2} \pi^{2}+K L^{4} S_{A}\right)+i^{2} \pi^{2} R^{2}\left(b^{2} K L^{2}+E I_{x}\left(i^{2} \pi^{2}+K L^{2} S_{A}\right)\right)\right)}{\left(L^{2}-i^{2} \pi^{2} R^{2}\right)^{2}}, \\
& \gamma_{m 4}=\frac{-b L^{2} R\left(i^{2} \pi^{2} R^{2}\left(b^{2} K L^{2}+i^{2} \pi^{2} E I_{x}\right)+E I_{T}\left(i^{2} L^{2} \pi^{2}+K L^{4} R^{2} S_{y}\right)\right)}{L^{2}-i^{2} \pi^{2} R^{2}}, \\
& \gamma_{m 5}=\frac{b i^{2} L^{2} \pi^{2} R^{2}\left(L^{2} E I_{T}+i^{2} \pi^{2} R^{2} E I_{x}+K L^{2} R^{2}\left(b^{2} \pi^{2} R^{2}\right.\right.}{\left.\left.L^{2} I_{x} S_{A}\right)\right)} .
\end{aligned}
$$

\section{Competing Interests}

The authors declare that they have no competing interests.

\section{Acknowledgments}

The research described in this paper was financially supported by the National Natural Science Foundation of China (51378236) and project supported by the transportation science and technology plan of Jilin province (2012-4-1-4).

\section{References}

[1] A. Chakrabarti, A. H. Sheikh, M. Griffith, and D. J. Oehlers, "Analysis of composite beams with longitudinal and transverse partial interactions using higher order beam theory," International Journal of Mechanical Sciences, vol. 59, no. 1, pp. 115-125, 2012.

[2] E. Oñate, A. Eijo, and S. Oller, "Simple and accurate two-noded beam element for composite laminated beams using a refined zigzag theory," Computer Methods in Applied Mechanics and Engineering, vol. 213-216, pp. 362-382, 2012.

[3] N. M. Newmark, C. P. Seiss, and I. M. Veist, "Tests and analysis of composite beams with incomplete interactions," Proceedings of the Society for Experimental Stress Analysis, vol. 4, no. 1, pp. 75-92, 1951.

[4] J. R. Goodman and E. P. Popkov, "Layered beam systems with interlayer slip," Journal of Structural Division, vol. 24, no. 11, pp. 2535-2547, 1968.
[5] J. R. Goodman and E. P. Popov, "Layered wood systems with inter-layer slip," Wood Science, vol. 1, no. 3, pp. 148-158, 1969.

[6] U. A. Girhammar and V. K. A. Gopu, "Composite beamcolumns with interlayer slip-exact analysis," Journal of Structural Engineering, vol. 199, no. 4, pp. 1265-1282, 1993.

[7] U. A. Girhammar and D. Pan, "Dynamic analysis of composite members with interlayer slip," International Journal of Solids and Structures, vol. 30, no. 6, pp. 797-823, 1993.

[8] Y. C. Wang, "Deflection of steel-concrete composite beams with partial shear interaction," Journal of Structural Engineering, vol. 124, no. 10, pp. 1159-1165, 1998.

[9] A. Dall'Asta, "Composite beams with weak shear connection," International Journal of Solids and Structures, vol. 38, no. 32-33, pp. 5605-5624, 2001.

[10] J. Nie and C. S. Cai, "Steel-concrete composite beams considering shear slip effects," Journal of Structural Engineering, vol. 129, no. 4, pp. 495-506, 2003.

[11] G. Ranzi and M. A. Bradford, "Analytical solutions for the time-dependent behaviour of composite beams with partial interaction," International Journal of Solids and Structures, vol. 43, no. 13, pp. 3770-3793, 2006.

[12] H.-B. Liu, W.-H. Liu, and Y.-L. Zhang, "Calculation analysis of shearing slip for steel-concrete composite beam under concentrated load," Applied Mathematics and Mechanics: English Edition, vol. 26, no. 6, pp. 735-740, 2005.

[13] F. Campi and I. Monetto, "Analytical solutions of two-layer beams with interlayer slip and bi-linear interface law," International Journal of Solids and Structures, vol. 50, no. 5, pp. 687-698, 2013. 
[14] A. Ayoub, "A two-field mixed variational principle for partially connected composite beams," Finite Elements in Analysis and Design, vol. 37, no. 11, pp. 929-959, 2001.

[15] G. Ranzi, M. A. Bradford, and B. Uy, "A direct stiffness analysis of a composite beam with partial interaction," International Journal for Numerical Methods in Engineering, vol. 61, no. 5, pp. 657-672, 2004.

[16] B. Čas, M. Saje, and I. Planinc, "Non-linear finite element analysis of composite planar frames with an interlayer slip," Computers and Structures, vol. 82, no. 23-26, pp. 1901-1912, 2004.

[17] F. Gara, G. Ranzi, and G. Leoni, "Displacement-based formulations for composite beams with longitudinal slip and vertical uplift," International Journal for Numerical Methods in Engineering, vol. 65, no. 8, pp. 1197-1220, 2006.

[18] W. Chung and E. D. Sotelino, "Three-dimensional finite element modeling of composite girder bridges," Engineering Structures, vol. 28, no. 1, pp. 63-71, 2006.

[19] Y. Majdi, C.-T. T. Hsu, and M. Zarei, "Finite element analysis of new composite floors having cold-formed steel and concrete slab," Engineering Structures, vol. 77, no. 15, pp. 65-83, 2014.

[20] V. Z. Vlasov, Thin Walled Elastic Beams, Israel Program for Scientific Translation, Jerusalem, Israel, 1961.

[21] M.-Y. Kim, S.-B. Kim, and N.-I. Kim, "Spatial stability of shear deformable curved beams with non-symmetric thin-walled sections. I: stability formulation and closed-form solutions," Computers and Structures, vol. 83, no. 31-32, pp. 2525-2541, 2005.

[22] M. H. Kim, S. B. Kim, and N. I. Kim, "Spatial stability of shear deformable curved beams with non-symmetric thin walled sections, II: F.E. solutions and parametric study," Computers \& Structures, vol. 83, no. 31-32, pp. 2542-2558, 2005.

[23] A. M. Yu, X. G. Yang, and G. H. Nie, "Generalized coordinate for warping of naturally curved and twisted beams with general cross-sectional shapes," International Journal of Solids and Structures, vol. 43, no. 10, pp. 2853-2867, 2006.

[24] F. N. Gimena, P. Gonzaga, and L. Gimena, "3D-curved beam element with varying cross-sectional area under generalized loads," Engineering Structures, vol. 30, no. 2, pp. 404-411, 2008.

[25] F. N. Gimena, P. Gonzaga, and L. Gimena, "Stiffness and transfer matrices of a non-naturally curved 3D-beam element," Engineering Structures, vol. 30, no. 6, pp. 1770-1781, 2008.

[26] L. Gimena, F. N. Gimena, and P. Gonzaga, "Structural analysis of a curved beam element defined in global coordinates," Engineering Structures, vol. 30, no. 11, pp. 3355-3364, 2008.

[27] V. Thevendran, N. E. Shanmugam, S. Chen, and J. Y. R. Liew, "Experimental study on steel-concrete composite beams curved in plan," Engineering Structures, vol. 22, no. 8, pp. 877-889, 2000.

[28] N. E. Shanmugam, M. Mahendrakumar, and V. Thevendran, "Ultimate load behaviour of horizontally curved plate girders," Journal of Constructional Steel Research, vol. 59, no. 4, pp. 509529, 2003.

[29] C. Topkaya, E. B. Williamson, and K. H. Frank, "Behavior of curved steel trapezoidal box-girders during construction," Engineering Structures, vol. 26, no. 6, pp. 721-733, 2004.

[30] F. Giussani and F. Mola, "Service-stage analysis of curved composite steel-concrete bridge beams," Journal of Structural Engineering, vol. 132, no. 12, pp. 1928-1939, 2006.

[31] R. E. Erkmen and M. A. Bradford, "Nonlinear elastic analysis of composite beams curved in-plan," Engineering Structures, vol. 31, no. 7, pp. 1613-1624, 2009. 


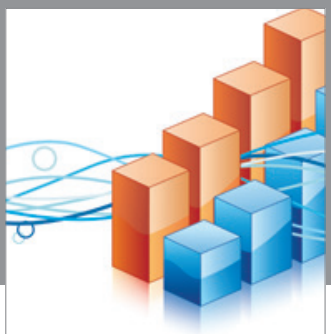

Advances in

Operations Research

vatem alat4

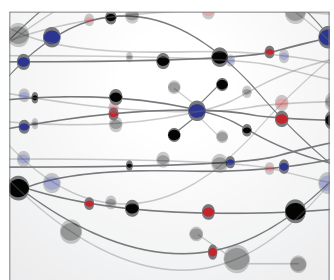

\section{The Scientific} World Journal
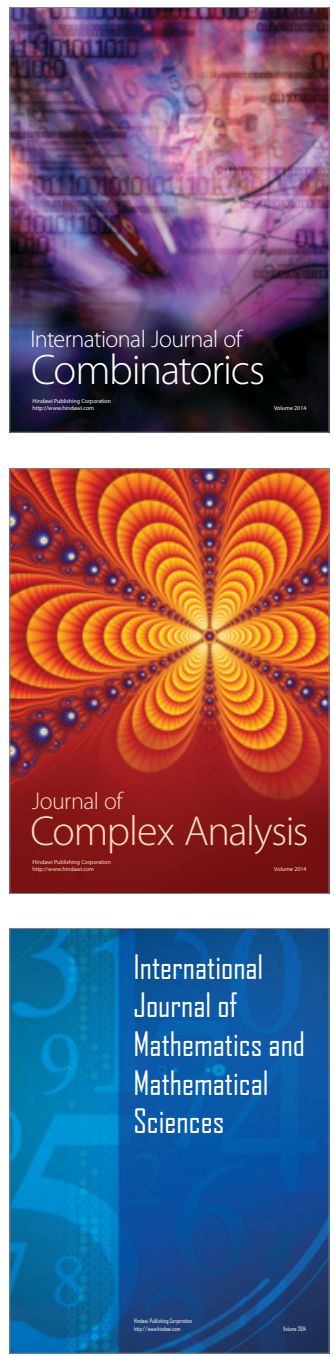
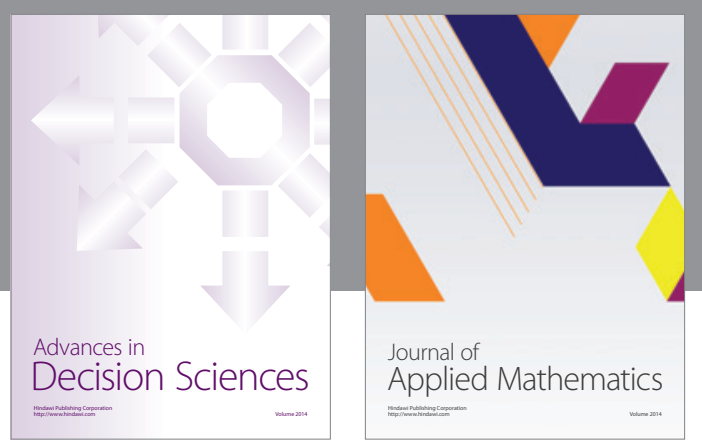

Algebra

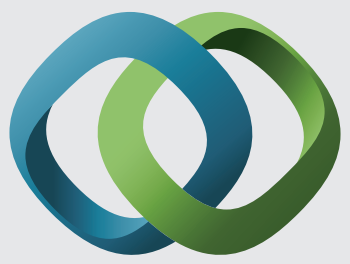

\section{Hindawi}

Submit your manuscripts at

http://www.hindawi.com
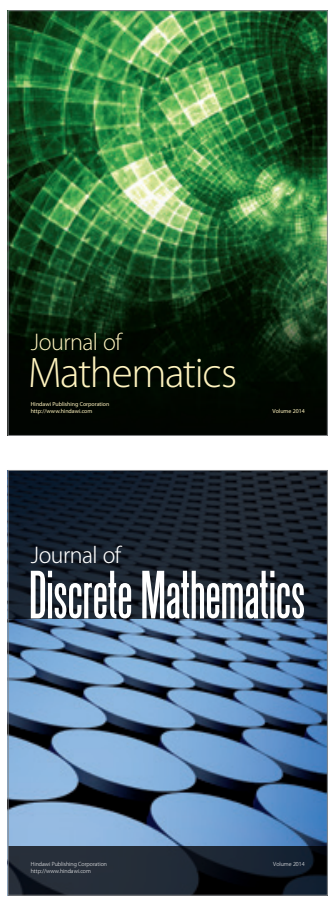

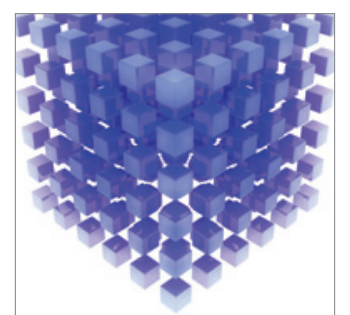

Mathematical Problems in Engineering
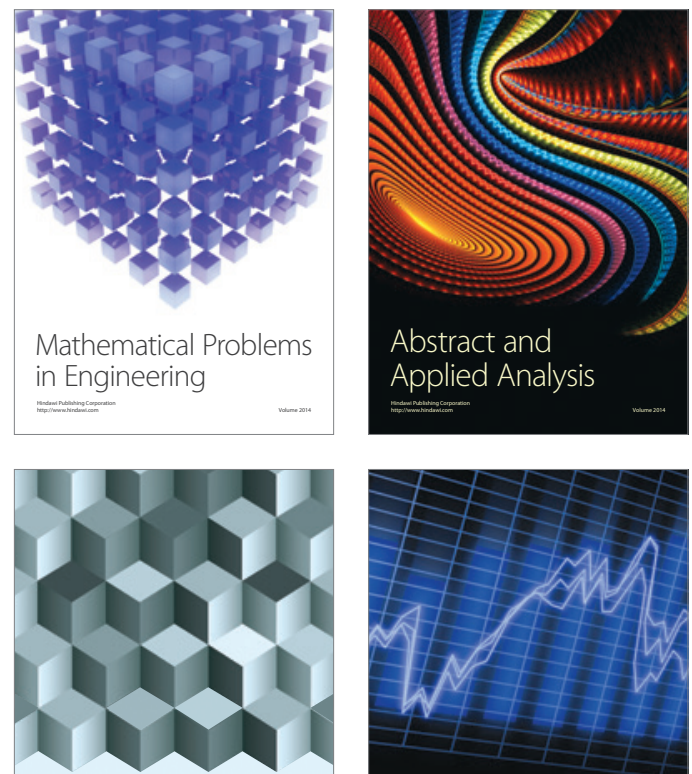

Journal of

Function Spaces

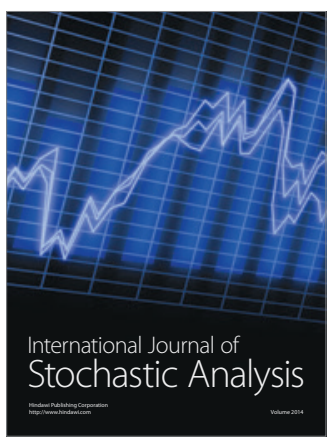

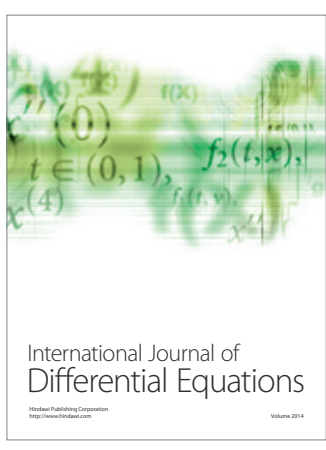
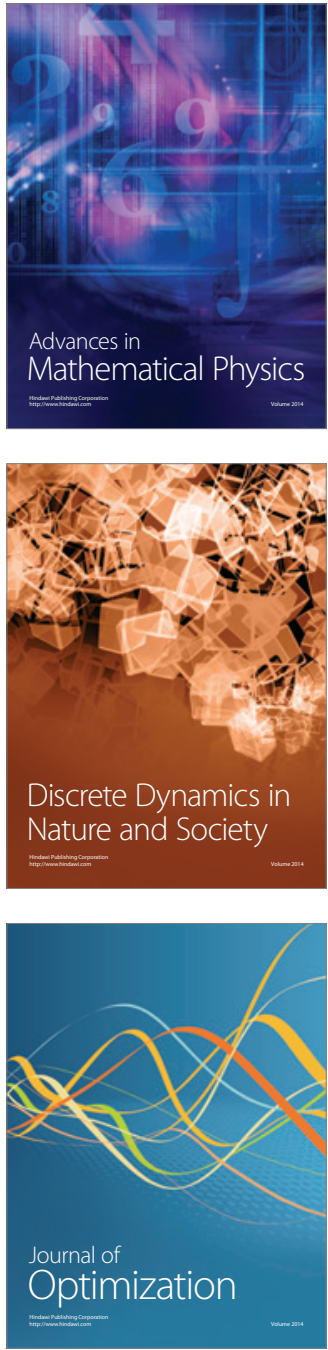